\title{
Hepatocyte Growth Factor-c-MET Signaling Mediates the Development of Nonsensory Structures of the Mammalian Cochlea and Hearing
}

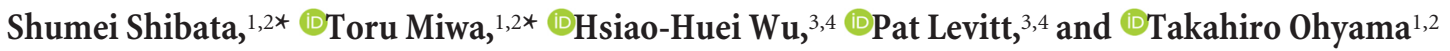 \\ ${ }^{1}$ Tina and Rick Caruso Department of Otolaryngology-Head and Neck Surgery, ${ }^{2 Z i l k h a ~ N e u r o g e n e t i c ~ I n s t i t u t e, ~ a n d ~}{ }^{3}$ Department of Pediatrics, Keck School \\ of Medicine, University of Southern California, Los Angeles, California 90033, and 4Program in Developmental Neurogenetics, Institute for the Developing \\ Mind, The Saban Research Institute, Children's Hospital of Los Angeles, Los Angeles, California 90027
}

The stria vascularis is a nonsensory structure that is essential for auditory hair cell function by maintaining potassium concentration of the scala media. During mouse embryonic development, a subpopulation of neural crest cell-derived melanocytes migrates and incorporates into a subregion of the cochlear epithelium, forming the intermediate cell layer of the stria vascularis. The relation of this developmental process to stria vascularis function is currently unknown. In characterizing the molecular differentiation of developing peripheral auditory structures, we discovered that hepatocyte growth factor $(\mathrm{Hgf})$ is expressed in the future stria vascularis of the cochlear epithelium. Its receptor tyrosine kinase, $c$-Met, is expressed in the cochlear epithelium and melanocyte-derived intermediate cells in the stria vascularis. Genetic dissection of HGF signaling via c-MET reveals that the incorporation of the melanocytes into the future stria vascularis of the cochlear duct requires c-MET signaling. In addition, inactivation of either the ligand or receptor developmentally resulted in a profound hearing loss at young adult stages. These results suggest a novel connection between HGF signaling and deafness via melanocyte deficiencies.

Key words: auditory; melanocyte; neural crest; receptor tyrosine kinase; stria vascularis

\section{Significance Statement}

We found the roles of hepatocyte growth factor (HGF) signaling in stria vascularis development for the first time and that lack of HGF signaling in the inner ear leads to profound hearing loss in the mouse. Our findings reveal a novel mechanism that may underlie human deafness DFNB39 and DFNB97. Our findings reveal an additional example of context-dependent c-MET signaling diversity, required here for proper cellular invasion developmentally that is essential for specific aspects of auditory-related organogenesis.

\section{Introduction}

The neural crest (NC) is comprised of specialized cells that arise from the lateral border of the neural plate and migrate into spe-

\footnotetext{
Received Dec. 9, 2015; revised June 24, 2016; accepted June 28, 2016.

Author contributions: T.O. designed research; S.S., T.M., and T.O. performed research; H.-H.W. and P.L. contributed unpublished reagents/analytic tools; T.0. analyzed data; P.L. and T.O. wrote the paper.

This work was supported by the Bundy Foundation, the Hearing and Health Foundation (H.-H.W.), National Institutes of Health Grant DC012085 (T.O.), the Simms/Mann Chair in Developmental Neurogenetics (P.L.), the University of Southern California (USC) Caruso Department of Otolaryngology-Head and Neck Surgery, and the House Ear Institute. We thank Charlene Cruz, Juemei Wang, and Ping Luo for excellent technical assistance, Andrew Groves for helpful comments, and Andreas Kispert and Ursula Dräger for probes. We are indebted to the late Dr. John K. Niparko for his outstanding support as chairman of the USC Tina and Rick Caruso Department of OtolaryngologyHead and Neck Surgery.

The authors declare no competing financial interests.

*S.S. and T.M. contributed equally to this work.

Correspondence should be addressed to Takahiro Ohyama at the above address. E-mail: takahiro.ohyama@med.usc.edu.
}

cific locations during vertebrate embryonic development. NC cells differentiate to form a broad array of derivatives, including neurons and glia of the peripheral nervous system, smooth muscle, cartilage, craniofacial mesenchyme, and melanocytes (Mayor and Theveneau, 2013). NC cells contribute to several inner ear structures during embryonic development. For instance, NC cells differentiate into Sox $10^{+}$glial cells in auditory and vestibular ganglia (Sandell et al., 2014) and Tyrosinase-related protein 1 (Tyrp1)-positive melanocytes in the stria vascularis (Tachibana, 1999). Correlations between melanocyte deficiency and deafness have been reported previously, related to mutations in human

S. Shibata's present address: Department of Otorhinolaryngology and Head and Neck Surgery, Graduate School of Medical Sciences, Kyushu University, 3-1-1 Maidashi, Fukuoka 812-8582, Japan.

T. Miwa's present address: Department of Otolaryngology-Head and Neck Surgery, Kumamoto University, 1-1-1 Honjo, Kumamoto 860-8556, Japan.

DOI:10.1523/JNEUROSCI.4410-15.2016

Copyright $\odot 2016$ the authors $\quad 0270-6474 / 16 / 368200-10 \$ 15.00 / 0$ 
disorders, such as Waardenburg syndrome (Pingault et al., 2010). Melanocytes derived from NC cells form the intermediate cell layer of the stria vascularis in the cochlea (Tachibana, 1999). The stria vascularis is a nonsensory structure of the mammalian cochlear duct that maintains endolymph homeostasis (Patuzzi, 2011). While it has been reported that the lack of intermediate cells disrupts the functions of stria vascularis, causing deafness (Steel and Barkway, 1989; Tachibana, 1999), the mechanism that underlies their development has been unknown. As part of our effort to study the molecular determinants of cochlear development, we focus here on hepatocyte growth factor (HGF) and its receptor tyrosine kinase, c-MET (MET). MET is involved in epithelial-mesenchymal transitions during development (Sonnenberg et al., 1993) and the development of neural crest-derived lineages (Kos et al., 1999). We and others have shown that this growth factor-receptor signaling system is involved in neuronal differentiation, including dendritic morphology, synapse formation and maturation, and functional circuit maturation (Tyndall and Walikonis, 2006; Judson et al., 2010; Qiu et al., 2011; Peng et al., 2014) c-MET has also been implicated in autism risk (Campbell et al., 2006, 2010; Rudie et al., 2012). Recently, Schultz et al. (2009) showed that an autosomal-recessive, nonsyndromic hearing loss, DFNB39, is caused by noncoding mutations of HGF. The same group generated conditional $H g f$ knock-out mice with Foxg1-Cre mice and found that the lack of $\mathrm{Hg}$ in the mouse inner ear caused deafness, a thinner stria vascularis, degeneration of outer hair cells, and a hypoplastic spiral ganglion (Schultz et al., 2009). Mujtaba et al. (2015) identified missense mutations in the $c$-MET locus from the DFNB97 family. Here, we show that both ligand and receptor are expressed in a complementary pattern in the region of the future stria vascularis of developing mouse cochlea. Moreover, tissue-specific gene disruption of $\mathrm{Hgf}$ or $\mathrm{c}-\mathrm{Met}$ revealed a crucial role of receptor signaling for proper incorporation of melanocytes into the stria vascularis, which, when disrupted, results functionally in deafness.

\section{Materials and Methods}

Mice. The following lines of mice were used in this study: Pax2-Cre [Research Resource Identifier (RRID), MMRRC_010569-UNC; CD1 background], $c$-Met-floxed (Jackson stock \#16974; RRID, IMSR_JAX: 016974; B6 background), Wnt1-Cre (Jackson stock \#22137; RRID, IMSR_JAX:0022137; B6C3 hybrid), Z/EG (Jackson stock \#3920; RRID, IMSR_JAX:003920), ROSA ${ }^{\mathrm{mT} / \mathrm{mG}}$ (Jackson stock \#7676; RRID, IMSR_JAX:007676), and Hgf-floxed (RRID, MMRRC_000423-UNC; B6/129 hybrid). Genotyping was performed based on the primer information provided by Mutant Mouse Resource and Research Center (MMRRC) and The Jackson Laboratory for each stock mouse line. All mice were maintained with free access to food and water and were used for experiments under approved House Research Institute and University of Southern California Institutional Animal Care and Use Committee protocols.

Generation of $\mathrm{Hgf}$ and c-Met conditional knock-out mice. Conditional knock-out mice were generated by the following mating procedure. Each Cre line of either sex was crossed with a given floxed/floxed allele to generate a Cre ${ }^{+/-}$; floxed $/{ }^{+}$line. Then $\mathrm{Cre}{ }^{+/-}$; floxed $/{ }^{+}$mice of either sex were crossed with floxed/floxed mice to generate the conditional allele. Pax2-Cre mice were used to generate cochlear epithelium-specific deletions of $H g f$ and $c$-Met. Wnt1-Cre was used to generate a neural crest-specific deletion of $c$-Met. All data were obtained from a mix of male and female mice.

In situ hybridization and Immunohistochemistry. Embryonic day 13.5 (E13.5) to postnatal day 1 (P1) heads were fixed in 4\% paraformaldehyde in PBS overnight at $4^{\circ} \mathrm{C}$, sunk in $30 \%$ sucrose in PBS at $4^{\circ} \mathrm{C}$, incubated in Tissue-Tek O.C.T. compound (Sakura Finetek) at room temperature for $10 \mathrm{~min}$, and frozen on dry ice. Sections, $14 \mu \mathrm{m}$ thick, were cut using a
Leica 3050 S cryostat. For the cochlear surface preparation, E18.5 or 8 week inner ears were fixed in $4 \%$ paraformaldehyde in PBS overnight at $4^{\circ} \mathrm{C}$, and Reissner's membrane and the stria vascularis were removed. Digoxigenin-labeled antisense riboprobes were synthesized using standard protocols (Stern, 1998). The following probes were used: $\mathrm{Hgf}, \mathrm{c}$-Met (Wu and Levitt, 2013), Igf-1 [Open Biosystems ID \#4194295; 3' side of the BamHI site $(\sim 1 \mathrm{~kb})$ was used], Aldhla2 (gift from U. Dräger, University of Massachusetts Medical School, Worcester, Massachusetts), Connexin 26, Claudin 11, and Dct (gift from A. Kispert, Hannover Medical School, Hannover, Germany). Additional details regarding probes will be provided upon request.

The in situ hybridization procedure was modified from a published protocol (Henrique et al., 1995). Detailed protocols are available upon request. For immunohistochemistry, antibodies used in this study were c-Met (R\&D Systems, catalog \#AF527; 1:100), Claudin 11 (Abcam, catalog \#ab53041; RRID, AB_2276205; 1:500), Kcnq1 (Sigma, catalog \#SAB2501224; RRID, AB_10626617; 1:100), Kir4.1 (Abcam, catalog \#ab105102; RRID, AB_10714275; 1:300; Alomone Lab, catalog \#APC035; RRID, AB_2040120; 1:300). Alexa Fluor or HRP-labeled secondary antibodies (1:500) were from ThermoFisher Scientific. PBS, $0.1 \%$ Triton $\mathrm{X}-100$, and $10 \%$ serum solution were used for blocking and incubation with antibodies. Color detection for HRP-labeled secondary antibody was performed with ImmPACT (Vector Laboratories). Each figure panel represents the results from at least three animals. Sample images were captured digitally using the Leica confocal SP5, Zeiss confocal LSM780, Zeiss Axioplan2, and Keyence BZ9000.

$\mathrm{Dct}^{+}$cell counting. Serial frozen sections of E13.5 cochlea from each genotype (four embryos each) were stained with Dct by in situ hybridization. The number of $\mathrm{Dct}^{+}$cells near cochlear duct was counted in each section. Because the cochlear duct turns, in single sections in which two ducts exist, counts are corrected by a factor of 0.5 .

Hematoxylin and eosin staining and measurement of the width of the stria vascularis. Paraffin sections (5 $\mu \mathrm{m}$ thick) of 8-week-old cochlear duct of each genotype (four animals each) were prepared. Sections containing the midmodiolar region were stained using hematoxylin and eosin. Images from the histological material were captured using the Keyence BZ9000 microscope. The images were used to measure the width of the stria vascularis, with a mean and SE calculated for each genotype.

Hearing tests. Auditory brainstem response and distortion product otoacoustic emission (DPOAE) protocols were performed to measure the hearing ability of mutant mice of either sex and control littermates between 4 and 6 weeks of age. Measurement for $\mathrm{Hgf}$ conditional knock-out $(H g f-c K O)$ and $c$-Met; Pax2-Cre conditional knock out (Met-Epi-cKO) mice was performed at the House Research Institute (OPBRF system). Measurement for Met-Nc-cKO mice was performed at the University of Southern California (USC). Briefly, mice were anesthetized with an intraperitoneal injection of ketamine 80-100 $\mathrm{mg} / \mathrm{kg}$ and xylazine $5-10 \mathrm{mg} / \mathrm{kg}$. The core body temperature was maintained with a thermostatically controlled heating blanket. Mice were then placed on a warmed blanket, and stainless-steel electrodes were placed subcutaneously at the vertex of the head and the auricle of one ear with a ground electrode at the base of the tail. A speaker/ microphone combo with a customized special adapter was positioned in the animal's ear canal. The sonic stimulus was delivered through the speaker as tone pips with a rise and a fall time of $0.5 \mathrm{~ms}$ and a total duration of $5 \mathrm{~ms}$ at $4,8,12,16,24$, and $32 \mathrm{kHz}$. Tone pips were delivered from 20 to $110 \mathrm{~dB}$ SPL with $10 \mathrm{~dB}$ intervals at a rate of 35 per second (OPBRF system) or from 20 to $100 \mathrm{~dB}$ SPL with $5 \mathrm{~dB}$ intervals at a rate of 30 per second (USC system). Sound-induced electrical responses were detected by the electrodes, recorded, and analyzed by the automated software programs BioSigRP Software (Tucker Davis Technologies for the OPBRF system) and EPL Cochlear Function Test Suite (Massachusetts Eye and Ear for the USC system). DPOAE at $2 f_{1}-f_{2}$ was collected by the microphone built into the speaker/ microphone combo. Two primary frequencies presented to the ear were $f_{1}$ and $f_{2}$. The $f_{1}$ level was $10 \mathrm{~dB}$ greater than the $f_{2}$ level; $f_{2} / f_{1}=$ 1.2. The $f_{1} / f_{2}$ levels were $35 / 25,45 / 35,55 / 45,65 / 55,75 / 65$, and $85 / 75$ $\mathrm{dB}$ (for OPBRF system) or 30/20, 40/30, 50/40, 60/50, 70/60, and 

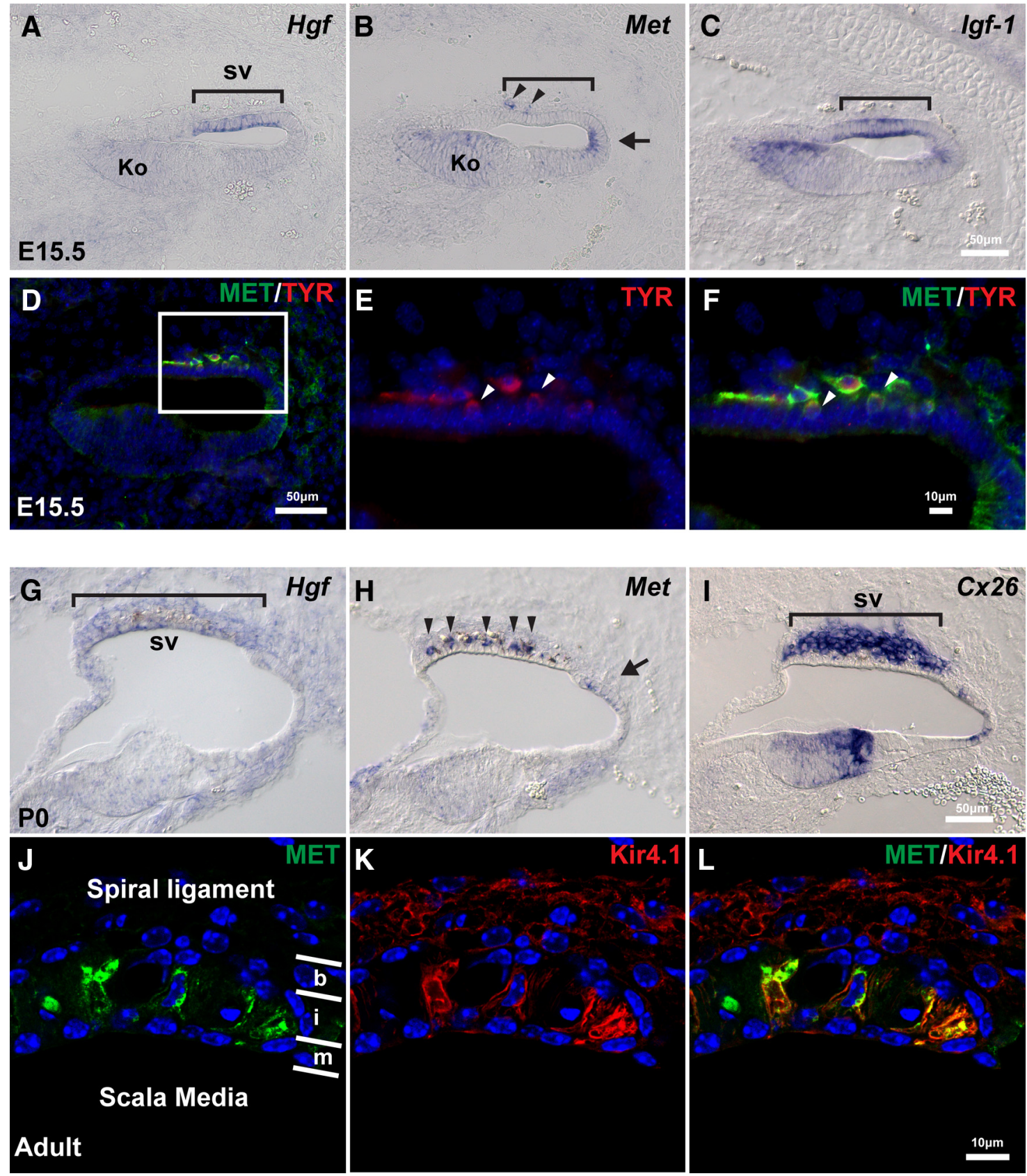

Figure 1. Hgf and c-Met are expressed in the developing mouse cochlea. A, At E15.5, Hgf is expressed in the future stria vascularis (sv; bracket). B, $c-$ Met is expressed weakly in the entire cochlear epithelium. Slightly higher expression is observed in Kölliker's organ (Ko) and the domain adjacent to future stria vascularis (arrow). A few c-Met ${ }^{+}$cells are observed in mesenchyme adjacent to the future stria vascularis region (arrowheads). C, Igf- 7 is expressed in the future stria vascularis (bracket). $\boldsymbol{D}, \mathrm{c}-\mathrm{Met}^{+}$(green) cells in the mesenchyme (similar cells in $\boldsymbol{B}$ ) express a melanocyte marker, tyrosinase (red). $\boldsymbol{E}, \boldsymbol{F}$, Higher magnification of the region of future stria vascularis indicated with a rectangle in $\boldsymbol{D}$. Some of the - Met $^{+}$; Tyrosinase ${ }^{+}$cells appear to becoming incorporated into the epithelium (arrowheads). G, At P0, Hgf is weakly expressed in the stria vascularis (bracket). $\boldsymbol{H}, \mathrm{c-Met}$ is expressed in the intermediate layer of the stria vascularis (arrowheads) and the domain adjacent to the stria vascularis (arrow) at P0. $I$, Connexin 26 (Cx26) is expressed in the basal layer of the stria vascularis. $J$ - $L$, Higher magnification of the stria vascularis in adult mice. Layers of basal cells (b), intermediate cells (i) and marginal cells ( $\mathrm{m}$ ) are divided by white lines. c-Met protein (green) is colocalized with an intermediate cell marker, Kir4.1 (red).

$80 / 70$ (for USC system). The $f_{2}$ frequencies were $4,8,12,16$, and 24 $\mathrm{kHz}$ (for OPBRF system) or 5.6, 8, 11.3, 16, 22.6, and $32 \mathrm{kHz}$ (for USC system). DPOAE thresholds were defined by the visual inspection of amplitude, which was always greater than the surrounding noise floor. Results from both ears were essentially same. The results from the right ear are presented.

\section{Results}

$H g f$ and $c$-Met are expressed in the developing cochlear duct In an ongoing effort to determine the molecular differences among structures in the developing cochlear duct, we analyzed the developmental patterns of expression of the growth factorreceptor combination of $H g f$ and $c$-Met. Expression of $H g f$ and $c$-Met is first detected in the cochlear duct at E15.5 (Fig. 1A), with little to no expression before this fetal age. Regional markers such as $I g f-1$ indicate $H g f$ expression is located in the prospective stria vascularis (Fig. $1 A-C$, brackets), whereas $c$-Met is in a spatially complementary position, in the region adjacent to the $H g f$-expressing domain (Fig. $1 B$, arrow). In addition, weak expression of both $\mathrm{Hgf}$ and $c$-Met is detected in Kölliker's organ at E15.5 (Fig. 1A,B, Ko), and a few $c$-Met ${ }^{+}$ 
cells are observed in the mesenchyme adjacent to the future stria vascularis region (Fig. $1 B$, arrowheads). Immunohistochemical analysis shows that the $c-\mathrm{Met}^{+}$cells in the mesenchyme express a melanocyte marker, tyrosinase, indicating these cells are the melanocytes (Fig. 1D-F). At late gestation and early postnatal stages, $c$-Met is expressed in a subset of the stria vascularis cells (Fig. $1 H$, arrowheads), whereas there is weak expression in the epithelium adjacent to the stria vascularis (Fig. $1 H$, arrow). Immunohistochemical analysis shows that c-MET is expressed in the adult organ of Corti. Double labeling with Kir4.1 shows that $\mathrm{c}-\mathrm{MET}^{+}$cells correspond to the intermediate cells in the stria vascularis (Fig. $1 J-L$ ).

\section{Intermediate cells are absent in the stria vascularis of Hgf-cKO mutant cochlea}

The patterns of expression of $\mathrm{Hg}$ and $c$-Met transcripts and proteins are consistent with a role of HGF-c-MET signaling in the development of the stria vascularis. To provide direct evidence for such a role, we first performed conditional genetic studies to delete the Hgf gene specifically in cochlear epithelium using Pax2-Cre mice (Ohyama and Groves, 2004). The impact of eliminating HGF-c-MET signaling in the mutant epithelium was analyzed by examining cell type-specific markers of the stria vascularis at $\mathrm{P} 1$. The stria vascularis consists of three different cell layers (Tachibana, 1999; Trowe et al., 2008, 2011), each of which can be selectively labeled by specific transcripts: a basal cell layer $\left(\mathrm{Cldn} 11^{+}\right.$, Connexin26 $\left.{ }^{+}\right)$, an intermediate cell layer $\left(\mathrm{Dct}^{+}\right.$, Kir4. $\left.1^{+}\right)$, and a marginal cell layer $\left(\right.$Aldh $\left.1 \mathrm{a}^{+}\right)$. At P1, the intermediate cell marker, $D c t$, is missing in the cochlea of the $\mathrm{Hgf}$-cKO mouse, whereas cell-type-specific markers of the basal and marginal cells are present normally (Fig. 2). Immunostaining of adult cochleas also show that marginal cells $\left(\mathrm{KCNQ}{ }^{+}\right)$and basal cells $\left(\right.$ Claudin $11^{+}$) are still present, but there is an enduring loss of intermediate cells $\left(\mathrm{Kir} 4.1^{+}\right)$in the $\mathrm{Hgf-cKO}$ mutant cochlea (Figs. 2E,F).

\section{Melanocytes fail to incorporate into the cochlear epithelium in the absence of HGF}

To determine the onset of defects of the stria vascularis in the $H g f-c K O$ mutant cochlea, we analyzed the expression of intermediate cell markers during early cochlear development. Intermediate cells are thought to be melanocytes derived from NC cells (Tachibana, 1999). At E13.5, Dct ${ }^{+}$melanocytes are observed around the ventral side of the cochlear epithelium (Fig. 3A, upper side, arrowheads). The number of melanocytes approaching the cochlear epithelium appears to be unaffected in the absence of HGF (Figs. 3 A,C). At E15.5, melanocytes are attached to the basal side of a domain of cochlear epithelium where the prospective stria vascularis forms (Fig. 3B). In the normal cochlea, these melanocytes begin integrating into the layer of future marginal cells of the cochlear epithelium from the basal turn of the cochlea at E15.5 (Fig. 3B, bracket). In contrast, melanocytes remain on the basal surface of the cochlear epithelium in Hgf-cKO mutant cochlea without forming an organized intermediate cell layer (Fig. $3 B$, arrowheads). At $\mathrm{P} 1$, few $D c t^{+}$cells are detected outside of the cochlear epithelium of the $\mathrm{Hgf}$-cKO mutant cochlea, although occasionally a few pigmented cells were observed as partially incorporated into the epithelium (Fig. 2D, arrowheads). This partial incorporation was unusual, and may be due to incomplete Cre-loxP recombination in the Pax2-Cre mice (Fig. 2G). These results indicate that melanocytes are present at the epithelialmesenchymal boundary, but fail to incorporate into the cochlear epithelium in the absence of HGF.
Melanocytes fail to incorporate into the cochlear epithelium due to NC cell-specific deletion of $c$-Met

The Pax2-Cre conditional gene knock-out system inactivates genes in otic placode-derived inner ear epithelium (Ohyama and Groves, 2004).c-Met is expressed not only in a part of cochlear epithelium, but also in melanocytes during and after integration of melanocytes into the stria vascularis (Figs. $1 B, E$ ). Thus, we analyzed the effects of conditionally deleting $c$-Met specifically in NC cells using the Wnt1-Cre line (Danielian et al., 1998; Chai et al., 2000). Expression of the neural crest marker gene (Dct) indicates that $c$-Met-deficient neural crest cells arrive at the base of the stria vascularis, but fail to incorporate into the epithelium. The disruption appears indistinguishable from $\mathrm{Hgf} \mathrm{cKO}$ driven by Pax2-Cre (compare Figs. 2, 3, Met-Nc-cKO). Together, the analyses of the two conditional mutant lines indicate that the signaling mediating melanocyte incorporation into the stria vascularis is due to HGF secretion from the cochlear epithelium that activates the $c$-Met receptor on $\mathrm{NC}$ cells.

\section{Epithelial-specific deletion of c-Met also causes defects in melanocyte incorporation into the stria vascularis}

As noted above, $c$-Met is expressed not only in the melanocytes, but also in the cochlear epithelium (Fig. 1B). To thoroughly examine a putative role for c-MET receptor activation in the different inner ear cell types, we next examined the effects of the loss of $c$-Met specifically in the cochlear epithelium using Pax2-Cre mice. We confirmed that $\mathrm{Hgf}$ expression in the cochlear epithelium is not affected in the Met-Epi-cKO mutant cochlea (data not shown). Surprisingly, there was a non-cell-autonomous effect on melanocyte incorporation in the stria vascularis due to the absence of $c$-Met specifically in cochlear epithelium (Figs. 2, 3, MetEpi-cKO). The lack of incorporation appears as robust as seen in the $\mathrm{Hgf}$ and $\mathrm{NC} c$-Met deletion lines. Immunostaining of adult cochleas revealed the presence of marginal cells $\left(\mathrm{KCNQ}^{+}\right)$and basal cells (Claudin $11^{+}$), but there is an enduring loss of intermediate cells $\left(\mathrm{Kir}_{4} \mathrm{1}^{+}\right)$in $\mathrm{Hgf-cKO}, \mathrm{Met}$-Nc-cKO, and Met-EpicKO mice, indicating that inactivation of $\mathrm{Hgf}$, $\mathrm{NC} c-\mathrm{Met}$, and epithelial $c$-Met all cause a failure of normal incorporation of melanocyte-derived intermediate cells in the stria vascularis (Figs. 2E,F).

\section{Loss of HGF-c-MET signaling in cochlear epithelium results in distinct malformations of the stria vascularis and tectorial membrane}

We further analyzed the phenotype of postnatal cochlea of $\mathrm{Hgf}$ and $c$-Met conditional mutant mice. The tectorial membrane that covers the apical surface of auditory hair cells (Fig. $4 A$ ) is malformed in the Hgf-cKO cochlea. We observed an abnormal cell layer surrounding the tectorial membrane, which appears to disrupt the attachment of the tectorial membrane to the hair cell stereocilia (Fig. 4B). These results are consistent with the observation of Schultz et al. (2009) using Foxg1-Cre mice to generate $H g f$-cKO mice. In contrast to $H g f$-cKO mutant mice, the morphology of the tectorial membrane in both Met$\mathrm{Nc}-\mathrm{cKO}$ and Met-Epi-cKO mutant mice appears normal (Fig. $4 B$ ). Measures of the width of the stria vascularis in adult $H g f-\mathrm{cKO}, \mathrm{Met}$-Nc-cKO, and Met-Epi-cKO mutant mice revealed a statistically significant thinning compared to wildtype mice (Fig. 4C). 

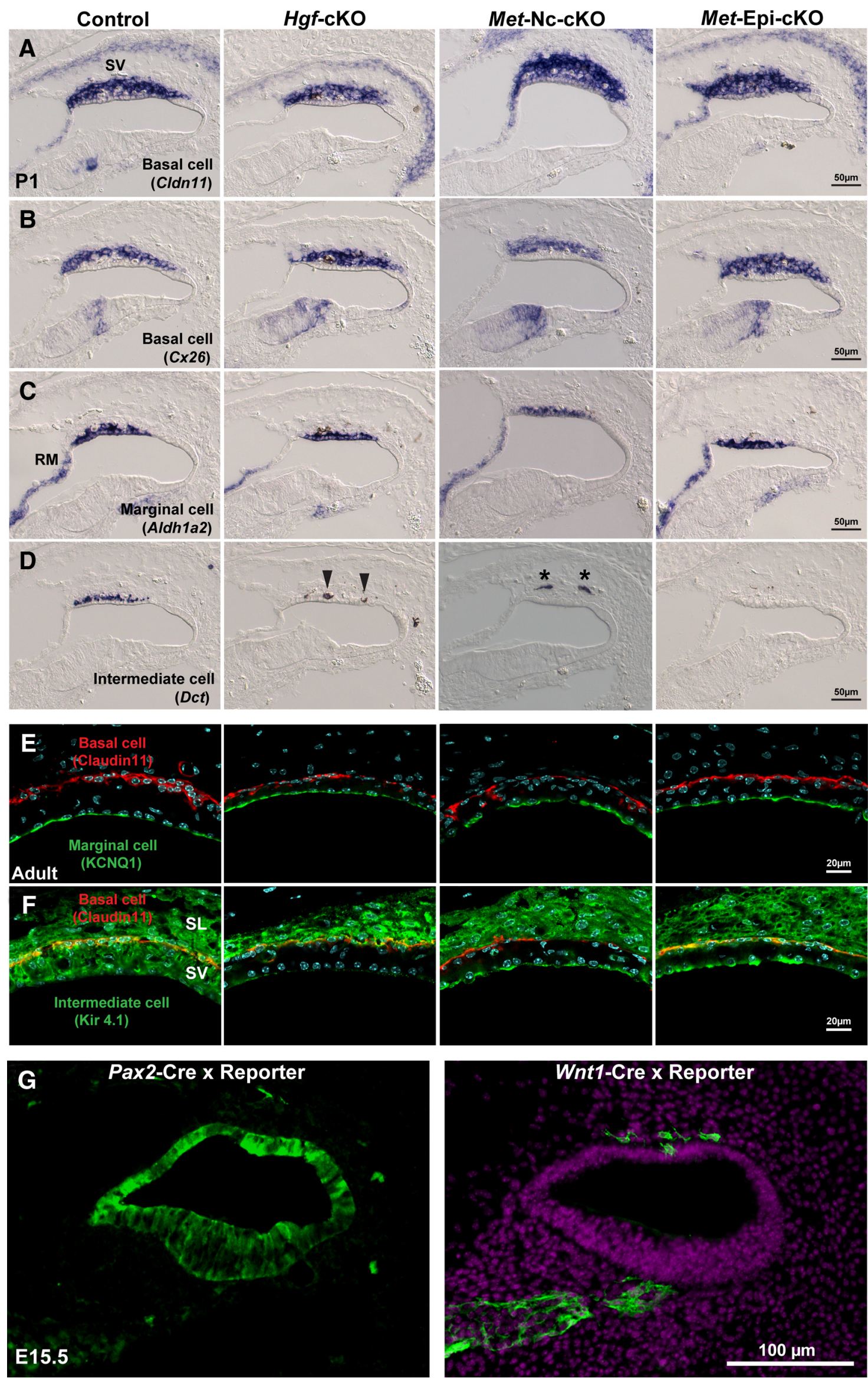


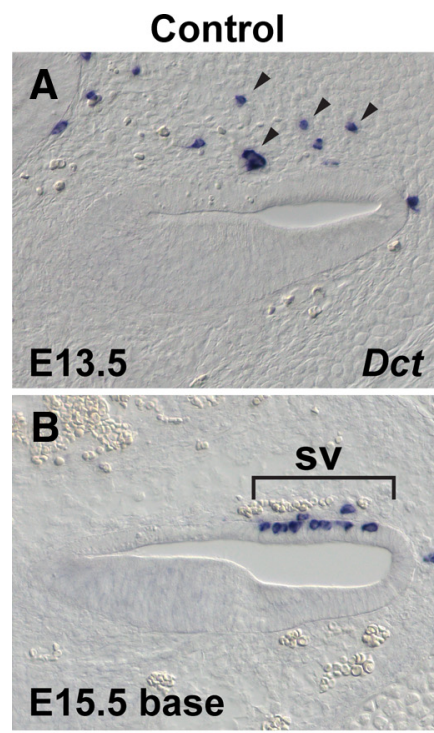

C
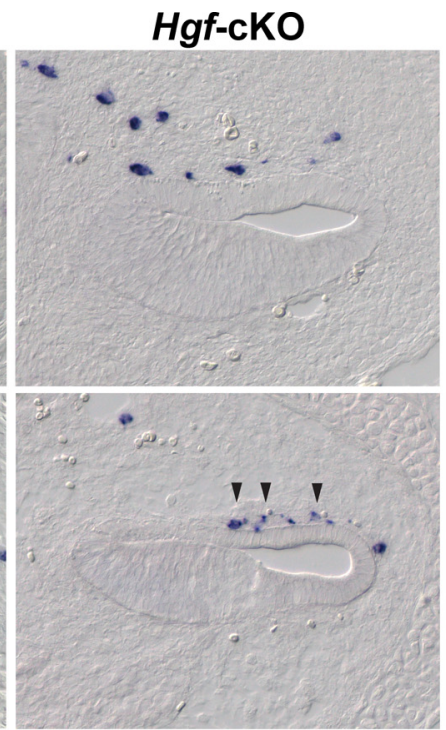
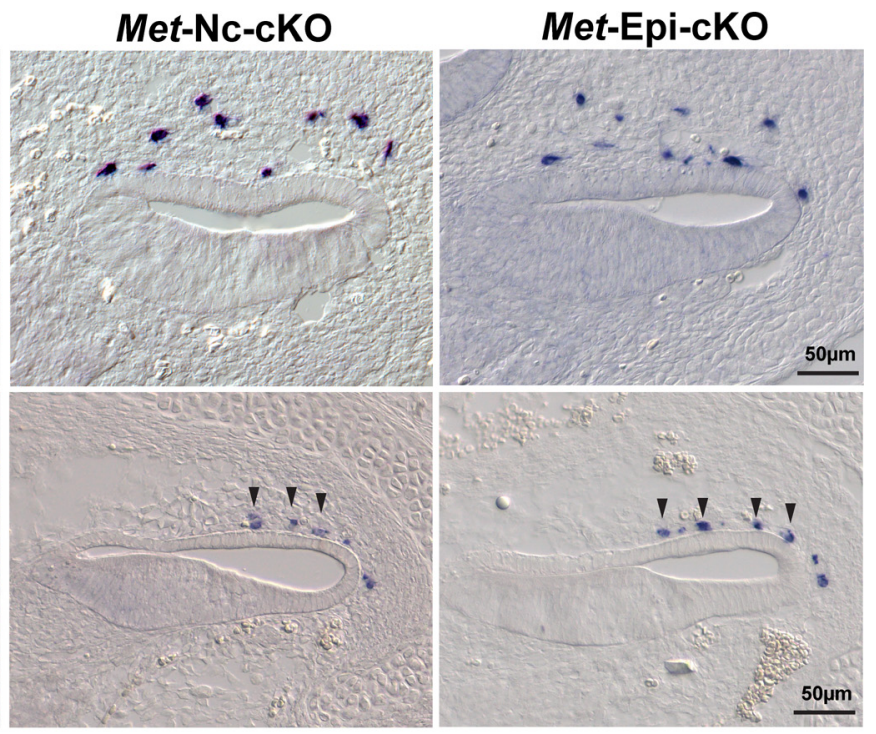

Hgf-cKO Met-Nc-cKO Met-Epi-cKO

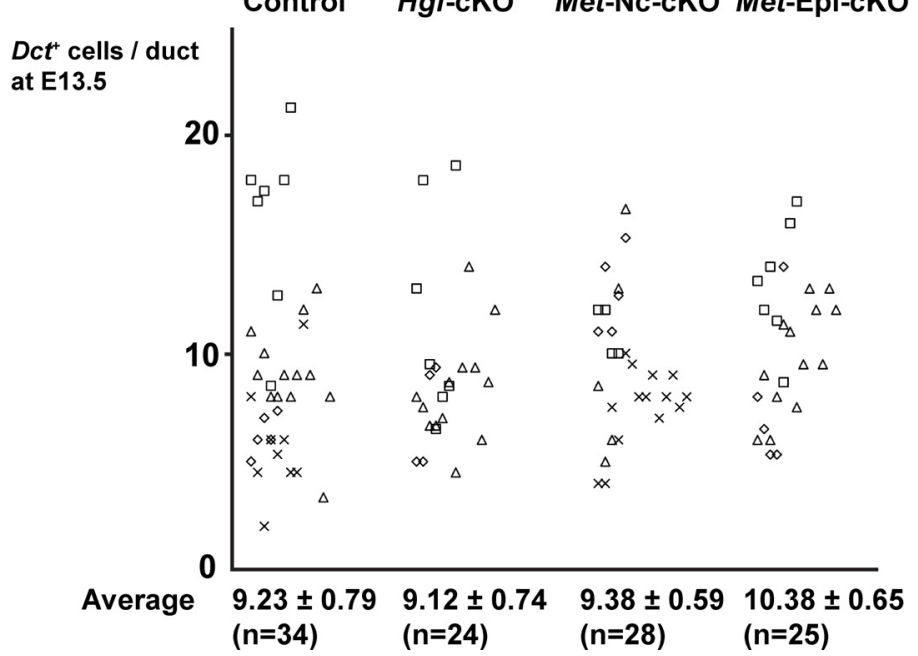

Figure 3. Melanocytes fail to be incorporated into the stria vascularis of Hgf or c-Met mutant mice. $A, A t E 13.5$, in situ hybridization of a melanocyte marker, Dct, indicates that a similar number of melanocytes (arrowheads) exists in mesenchyme adjacent to the cochlear epithelium of control, Hgf-cKO, Met-Nc-cKO, and Met-Epi-cKO mice. The mean number of Dct ${ }^{+}$cells is indicated in $\boldsymbol{C}$. $\boldsymbol{B}$, Depiction of melanocyte incorporation into the future stria vascularis (sv) from the basal turn of the cochlear duct (bracket) in control cochlea at E15.5. The melanocytes remain outside of the cochlear epithelium near the future stria vascularis region in the three conditional mutant mouse lines (arrowheads). C, The number of $D c t^{+}$cells near the E13.5 cochlear duct for each genotype (4 embryos represented by four different symbols) was counted from serial sections. Each number per cochlear duct was plotted, and the mean cell number per duct is presented with the SEM.

$\leftarrow$

Figure 2. Intermediate cells are absent in the cochlea of $\mathrm{Hgf}$ and $\mathrm{C}-$ Met mutants at postnatal day 1.A, B, At postnatal day 1, basal cell markers, Claudin11 (Cldn11) and Connexin26 (CX26), are expressed in the stria vascularis (sv) of Hgf; Pax2-Cre conditional knock-out mouse (Hgf(K0), neural crest cell-specificc-Met; Wnt1-Cre conditional knock-out mouse (Met-Nc-cKO), and cochlear epithelium-specific c-Met; Pax2-Cre conditional knock-out mouse (Met-Epi-cK0). C, A marginal cell marker, Aldh1a2, is expressed in the absence of HGF- C-MET signaling. D, An intermediate cell/melanocyte marker, Dct, is not observed in the stria vascularis of any of the three conditional mutant mouse lines. Note that a few pigmented cells in the Hgf-cKO may be incorporated into the epithelium (arrowheads) and a few cells remain in the mesenchyme near the cochlear epithelium (Met-Nc-cKO, asterisks). $\boldsymbol{E}$, Immunofluorescence images show a marginal cell marker, KCNQ1 (green), and a basal cell marker, Claudin11 (red), are expressed in adult stria vascularis. $\boldsymbol{F}$, An intermediate cell/melanocyte marker, Kir4.1 (green) is not expressed in the stria vascularis (SV) of any of the three conditional mutant mouse lines, while it is expressed in the spiral ligament (SL) of all four genotypes. G, Cre-loxP reporter signals (green) of E15.5 cochlear duct in Pax2-Cre and Wnt7-Cre animals. Note that Pax2-Cre does not exhibit 100\% efficiency in the cochlear epithelium. RM, Reissner's membrane.
Auditory hair cells develop normally at birth, but are malformed and degenerated in the adult mutant cochlea in the absence of HGF-c-MET signaling

We analyzed development of the auditory hair cells in Hgf- and c-Met-deficient cochleae. At birth, both inner and outer hair cells appear to be properly formed, and the morphology of the organ of Corti appears normal (Figs. $5 A, B$ ). However, by 8 weeks of age, the cell bodies of surviving hair cells appear to be malformed in contrast to control littermates (Figs. 5C,D). In $\mathrm{Hgf}$ and $c$-Met mutant cochlea, most outer hair cells have degenerated at the basal turn of the cochlea (Fig. $5 E$ ). In contrast, at the mid-to-apex turn, it appears that fewer inner and outer hair cells are missing (Figs. 5C,D).

Loss of HGF-c-MET signaling in the cochlea causes deafness Next, we examined the functional impact of the failure of intermediate cell development due to the absence of HGF-c-MET signaling. Constitutive $H g f$-null or $c$-Met-null mutant embryos die before birth (Bladt et al., 1995; Schmidt et al., 1995; Uehara et 


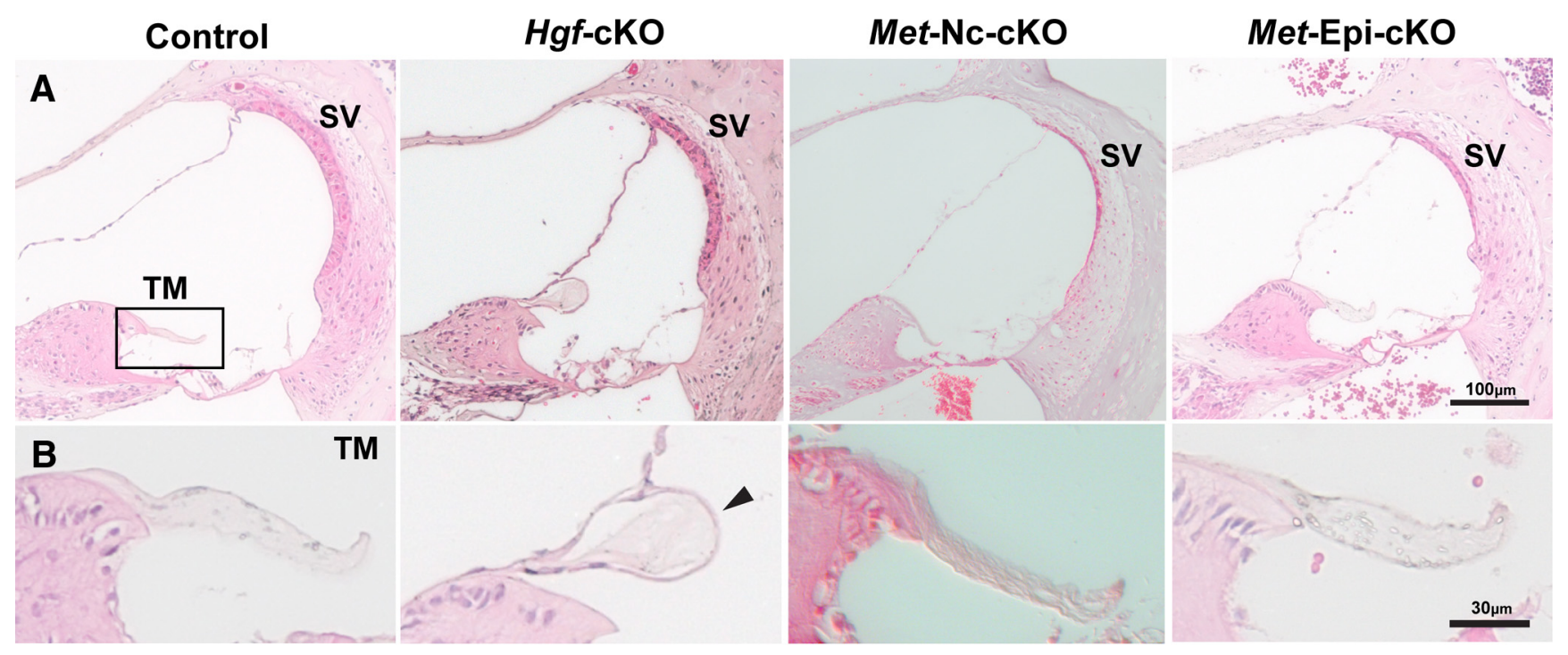

C

\section{Control Hgf-cKO Met-Nc-cKO Met-Epi-cKO}

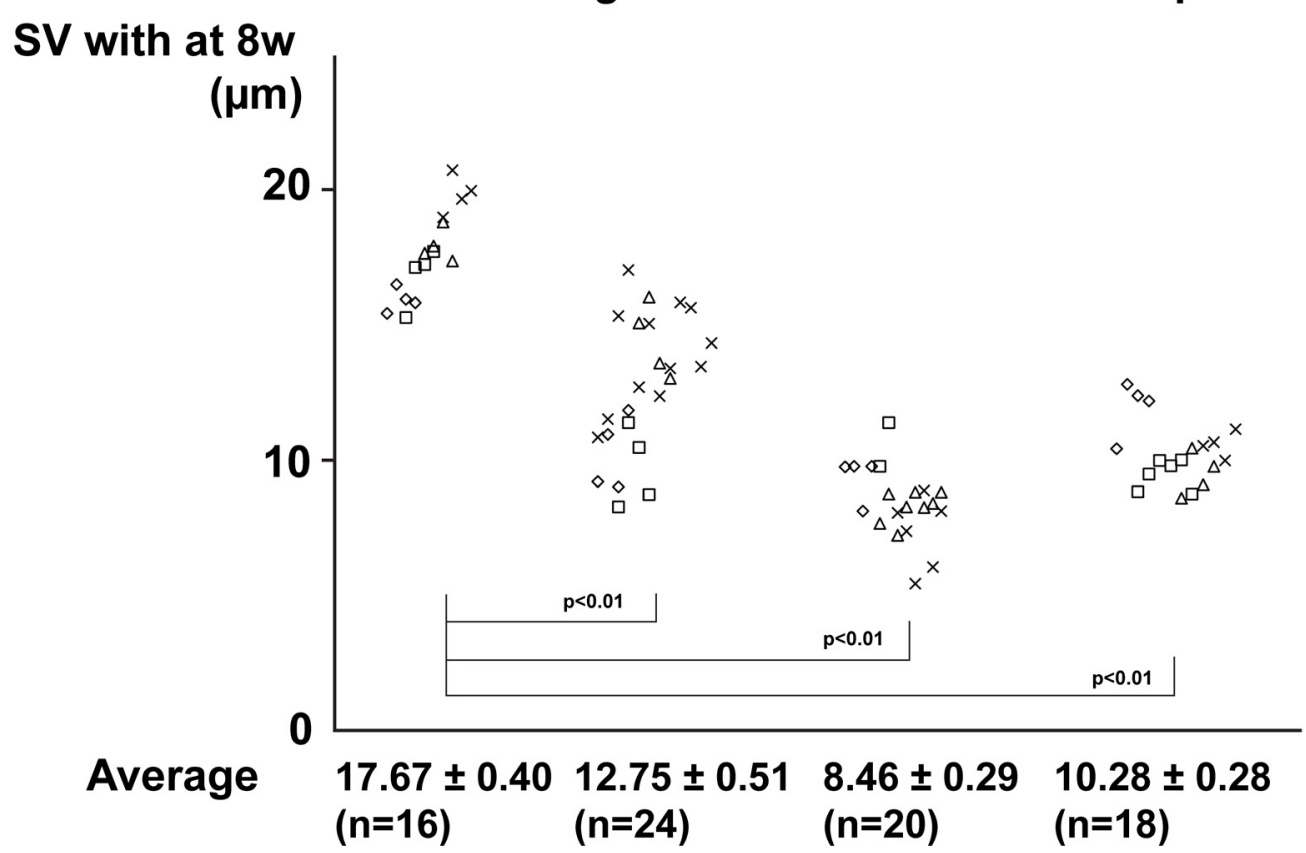

Figure 4. Absence of HGF-C-MET signaling causes thinning of the stria vascularis. A, Representative paraffin sections of hematoxylin and eosin-stained cochlear ducts from adult $\mathrm{Hgf-cKO}, \mathrm{Met}-\mathrm{Nc}-\mathrm{cKO}$, and Met-Epi-cKO mice. The images illustrate that the gross morphology of the mutant cochleae is similar to that of controls. $\boldsymbol{B}$, Higher-magnification images of tectorial membrane (TM; rectangle in $\boldsymbol{A}$ ) show an ectopic cell layer surrounding the tectorial membrane of $\mathrm{Hgf}$-cKO mice (arrowhead). $\boldsymbol{C}$, The widths of the stria vascularis (SV in $\boldsymbol{A}$ ) from 8-week-old cochlear ducts from each genotype (four animals represented by four different symbols) are plotted and expressed as the mean \pm SEM. The mean width of mutant stria vascularis in all three genotypes is significantly reduced (Student's $t$ test, $p<0.01$ ).

al., 1995). However, Hgf-cKO and $c$-Met-cKO mutant mice generated with Pax2-Cre and Wnt1-Cre mice survive postnatally. Thus, we were able to test auditory functions in young adult mutant mice at 4-6 week of age. Compared to wild-type mice, there is a threshold shift of $40-70 \mathrm{~dB}$ (SPL) across all tested frequencies measured in all mutants, indicating that mice in which either Hgf or $c$-Met is deleted suffer from profound hearing loss (Fig. 6). In addition, there are no detectable levels of distortion product otoacoustic emission at any of the frequencies analyzed in the mutant mice (data not shown).

\section{Discussion}

The molecular mechanisms underlying the complex development of the cochlea to achieve normal hearing have been chal- lenging to discern (Heller, 2013). Here, we have focused on the role of signaling through the receptor tyrosine kinase c-MET and its only known ligand, HGF. During cochlear development, NC cell-derived melanocytes are incorporated into the region of the future stria vascularis of cochlear epithelium to form the intermediate layer of the stria vascularis (Tachibana, 1999). Little is known about the original location and migrating pathway of the neural crest cells destined to migrate toward the stria vascularis. There appear to be three critical steps of melanocyte incorporation: (1) the melanocytes approach the stria vascularis region in response to unknown attractants; (2) the melanocytes adhere to the cochlear epithelium at specific locations; and (3) the melanocytes incorporate into the cochlear epithelium. The present study 


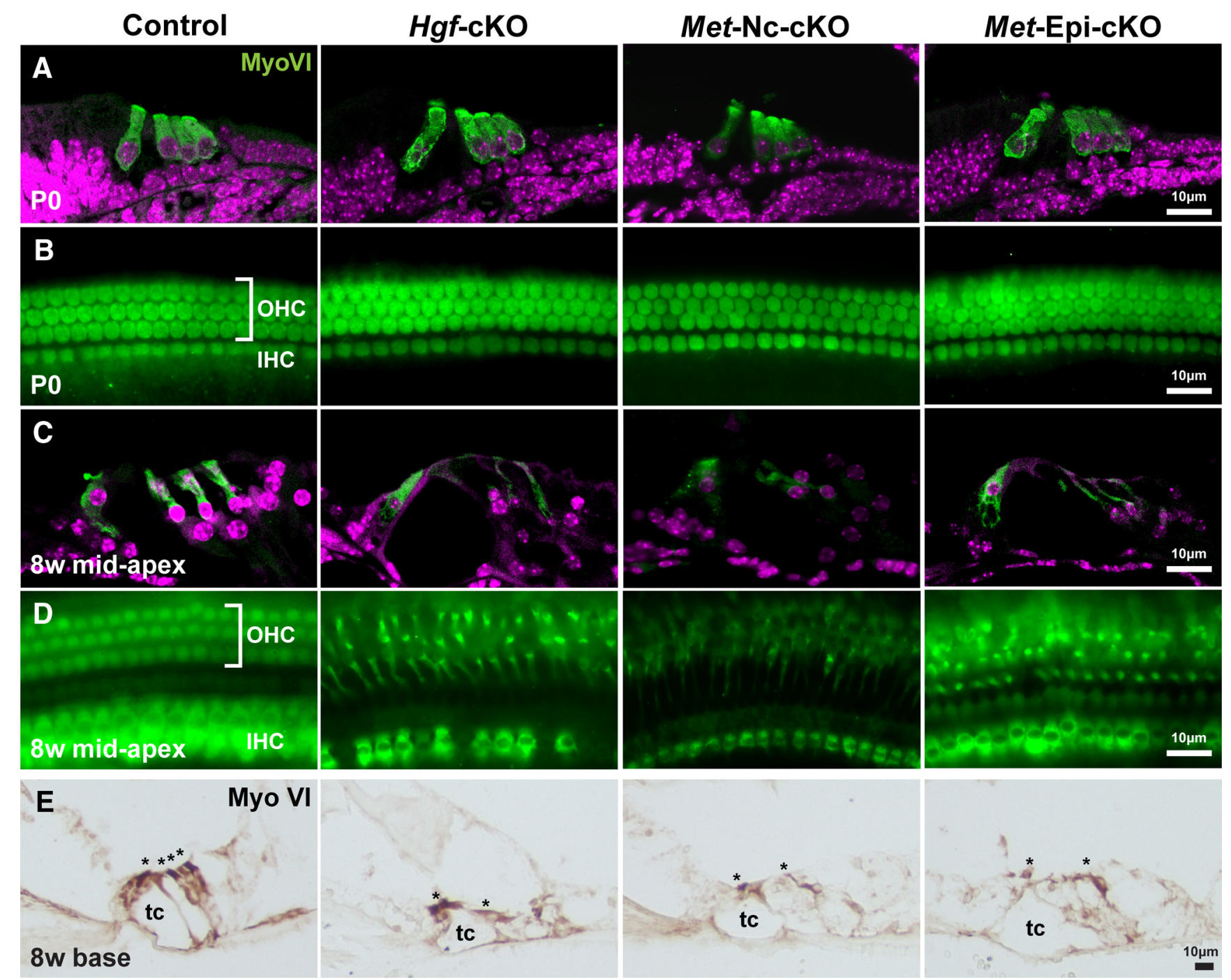

Figure 5. Auditory hair cells form at birth, then become malformed in adult $H g$ for $c-$ Met mutant cochleae. $A, B$, Immunofluorescent images of frozen sections $(\boldsymbol{A})$ and cochlear surface preparation $(\boldsymbol{B})$ of the organ of Corti indicateMyosin $\mathrm{VI}^{+}$(MyoVl; green) auditory hair cells in control, $\mathrm{Hgf-CKO}, \mathrm{Met-Nc-CKO}$, and Met-Epi-cKO mice at birth. One row of the inner hair cells (IHC) and three rows of the outer haircells (OHC) formed in the absence of HGF- C-MET signaling. C, D, At 8 weeks of age, the organ of Corti structure of the mid-to-apex region of the cochlear duct is disorganized in Hgf-cKO, Met-Nc-cKO, and Met-Epi-cKO mice. Although most of inner and outer hair cells exist in these mutant mice (D), the cell bodies of outer hair cells are substantially reduced in each of the three mutant lines $(\boldsymbol{C}) . \boldsymbol{E}$, Paraffin sections depict the cochlea at the basal turn. Here, most outer hair cells are degenerated in each of the mutants. Myosin $\mathrm{VI}^{+}$hair cells are marked by asterisks. tc, Tunnel of Corti; $8 \mathrm{w}, 8$ week.

A

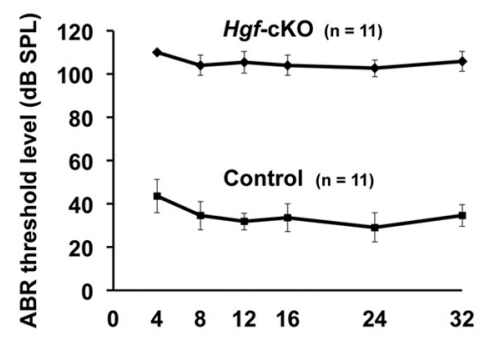

B

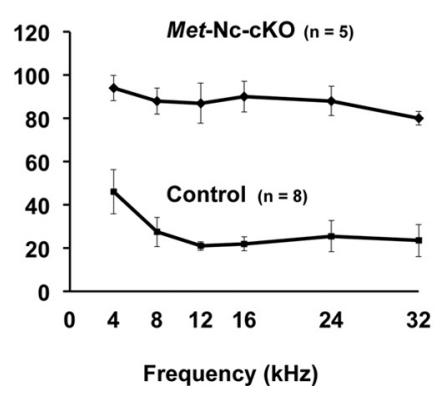

C

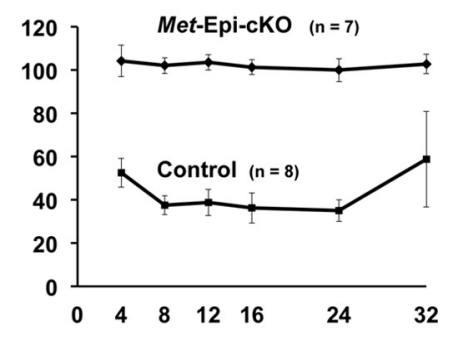

Figure 6. Hgf and $C-$ Met mutant mice display profound hearing loss. $A-C$, Measures of auditory brainstem responses indicate that the hearing threshold at 4 to 6 weeks of age in $H g f-c K 0$ ( $A$ ), Met-Nc-cKO ( $\boldsymbol{B})$ and Met-Epi-cKO ( $\boldsymbol{C}$ ) mice shift from $\sim 40$ to $80-110 \mathrm{~dB} \mathrm{SPL}$ at all frequencies tested ( 4 to $32 \mathrm{kHz}$ ). The numbers of animals tested are indicated. Error bars indicate SD.

suggests that $\mathrm{HGF}-\mathrm{c}$-Met signaling, either directly in melanocytes or indirectly in epithelial cells, is required specifically for step 3. The failure of the cells to form the intermediate cell layer by incorporation results subsequently in cochlear structural and profound hearing deficits.
Direct and indirect roles of the HGF-c-MET signaling pathway in melanocyte incorporation into cochlear epithelium

We found that HGF-c-MET signaling in either melanocytes or cochlear epithelial cells is necessary for melanocyte incorporation 
into cochlear epithelium. This was an unexpected result, suggesting that cell autonomous and nonautonomous mechanisms likely work in concert to direct proper integration of melanocytes. Melanocytes adhere to the future stria vascularis region of the cochlear epithelium in the absence of HGF-c-MET signaling. While currently unknown, the subsequent incorporation processes that is dependent on HGF-c-MET signaling may underlie cytoskeletal remodeling and modulation of extracellular matrix to promote cell invasion into the stria vascularis. A direct signaling effect on incorporation is consistent with the involvement of c-MET activation by HGF in cell migration and other motogenic processes (Bladt et al., 1995; Birchmeier and Gherardi, 1998; Beilmann et al., 2000; Zhang and Vande Woude, 2003). We identified greater $c$-Met expression in a domain adjacent to the future stria vascularis of cochlear epithelium compared to other regions of cochlear epithelium (Fig. $1 B$, arrow). It is not clear whether $\mathrm{HGF}-\mathrm{c}-\mathrm{MET}$ activation in this domain is required for melanocyte incorporation in a non-cell-autonomous manner.

Despite the fact that $H g f$ and $c$-Met mutant mice present profound deafness in all range of frequencies at young adult stages, hair cells remained in mid-to-apex region of the cochlea (Figs. $5 C, D)$. Determining whether the surviving hair cells retain mechanosensory functions will require additional studies. Kikkawa et al. (2009) reported that HGF protects hair cells from aminoglycoside ototoxicity. It is thus possible that HGF-c-MET signaling is important for longer-term survival of hair cells or under conditions of cytotoxic stress. Since a similar degree of hair cell loss occurs at the base of the cochlea in Hgf and c-Met mutant mice (Fig. 5E), it is likely that malformation and loss of the hair cells are caused indirectly by malfunction of the stria vascularis.

\section{Melanocyte deficiency and deafness}

As noted above, correlations between albinism and deafness have been described for over 150 years. The findings presented here provide a possible molecular mechanism for the relationship between NC-derived melanocytes and deafness. Human genetic studies show that rare mutations in HGF and $c$-MET (DFNB39 and DFNB97) cause deafness (Schultz et al., 2009; Mujtaba et al., 2015). Based on the three conditional mutant mouse models reported here, we suggest that defects in the stria vascularis is sufficient to cause hearing loss and may underlie deafness in these patients. A number of genes identified in Waardenburg syndrome indicate deficiencies in NC specification, such as $P A X 3$ and SNAI2, and melanocyte differentiation, such as MITF and SOX10 (Pingault et al., 2010). Mutations have been identified in EDNRB and EDN3 in Waardenburg syndrome types IVa and IVb, respectively (Shah et al., 1981; Pingault et al., 2010). In the mouse, Ednrb is expressed in NC cells, and Edn3 is expressed in the epithelial layer of the stria vascularis around E15 to E17 (data not shown). Thus, these genes also may be involved in melanocyte incorporation into the stria vascularis. Our present findings reveal that the mouse homologues of the deafness genes DFNB39 $(H g f)$ and DFNB97 (c-Met) mediate the final step of the incorporation process of neural crest cell-derived melanocytes into the stria vascularis. The normal developmental invasion of these $\mathrm{NC}$-derived cells is reminiscent of the pathological role that HGF-c-MET signaling plays in cancer metastasis (Mazzone and Comoglio, 2006; Gherardi et al., 2012). HGF is also called "scatter factor," promoting motility and invasiveness of the epithelial cells (Naldini et al., 1991; Trusolino et al., 2010). During embryogenesis, HGF-c-MET signaling is known to control the epithelial-to-mesenchymal transition and migration of myogenic precursors into the limb bud (Bladt et al., 1995; Dietrich et al., 1999). Activating mutations of MET can cause metastatic cancer progression, such as in head and neck cancers (Di Renzo et al., 2000). Peinado et al. (2012) reported that metastatic melanomas secret exosomes including active MET that "educate" bone marrow progenitor cells by increasing mobility and tumor niche by altering the extracellular matrix. Thus, the findings here suggest that such biological activity via c-MET receptor activation by $\mathrm{HGF}$ is a normal part of regulating an invasion mechanism that is crucial for organogenesis during embryonic development.

In conclusion, we have shown a unique role for the HGF and c-MET receptor tyrosine kinase signaling pathway in the development of the stria vascularis of the mouse cochlea, a nonsensory epithelium. The disruption of the formation of the intermediate cells thus results in deafness, which likely is relevant to syndromic human deafness caused by rare mutations in the HGF or $c-M E T$ genes. Further analysis is needed to discern the physiological correlates of remaining hair cell dysfunction, and the downstream molecular mechanisms mediating HGF-c-MET signaling that enable migrating melanocytes to integrate into the cochlear epithelium to form the stria vascularis.

\section{References}

Beilmann M, Vande Woude GF, Dienes HP, Schirmacher P (2000) Hepatocyte growth factor-stimulated invasiveness of monocytes. Blood 95:39643969. Medline

Birchmeier C, Gherardi E (1998) Developmental roles of HGF/SF and its receptor, the c-Met tyrosine kinase. Trends Cell Biol 8:404-410. CrossRef Medline

Bladt F, Riethmacher D, Isenmann S, Aguzzi A, Birchmeier C (1995) Essential role for the c-met receptor in the migration of myogenic precursor cells into the limb bud. Nature 376:768-771. CrossRef Medline

Campbell DB, Sutcliffe JS, Ebert PJ, Militerni R, Bravaccio C, Trillo S, Elia M, Schneider C, Melmed R, Sacco R, Persico AM, Levitt P (2006) A genetic variant that disrupts MET transcription is associated with autism. Proc Natl Acad Sci U S A 103:16834-16839. CrossRef Medline

Campbell DB, Warren D, Sutcliffe JS, Lee EB, Levitt P (2010) Association of MET with social and communication phenotypes in individuals with autism spectrum disorder. Am J Med Genet B Neuropsychiatr Genet 153B: 438-446. Medline

Chai Y, Jiang X, Ito Y, Bringas P Jr, Han J, Rowitch DH, Soriano P, McMahon AP, Sucov HM (2000) Fate of the mammalian cranial neural crest during tooth and mandibular morphogenesis. Development 127:1671-1679. Medline

Danielian PS, Muccino D, Rowitch DH, Michael SK, McMahon AP (1998) Modification of gene activity in mouse embryos in utero by a tamoxifeninducible form of Cre recombinase. Curr Biol 8:1323-1326. CrossRef Medline

Dietrich S, Abou-Rebyeh F, Brohmann H, Bladt F, Sonnenberg-Riethmacher E, Yamaai T, Lumsden A, Brand-Saberi B, Birchmeier C (1999) The role of SF/HGF and c-Met in the development of skeletal muscle. Development 126:1621-1629. Medline

Di Renzo MF, Olivero M, Martone T, Maffe A, Maggiora P, Stefani AD, Valente G, Giordano S, Cortesina G, Comoglio PM (2000) Somatic mutations of the MET oncogene are selected during metastatic spread of human HNSC carcinomas. Oncogene 19:1547-1555. CrossRef Medline

Gherardi E, Birchmeier W, Birchmeier C, Vande Woude G (2012) Targeting MET in cancer: rationale and progress. Nat Rev Cancer 12:89-103. CrossRef Medline

Heller S (2013) Special issue on inner ear development and regeneration. Hear Res 297:1-2. CrossRef Medline

Henrique D, Adam J, Myat A, Chitnis A, Lewis J, Ish-Horowicz D (1995) Expression of a Delta homologue in prospective neurons in the chick. Nature 375:787-790. CrossRef Medline

Judson MC, Eagleson KL, Wang L, Levitt P (2010) Evidence of cellnonautonomous changes in dendrite and dendritic spine morphology in the met-signaling-deficient mouse forebrain. J Comp Neurol 518:44634478. CrossRef Medline

Kikkawa YS, Nakagawa T, Tsubouchi H, Ido A, Inaoka T, Ono K, Ito J (2009) Hepatocyte growth factor protects auditory hair cells from aminoglycosides. Laryngoscope 119:2027-2031. CrossRef Medline 
Kos L, Aronzon A, Takayama H, Maina F, Ponzetto C, Merlino G, Pavan W (1999) Hepatocyte growth factor/scatter factor-MET signaling in neural crest-derived melanocyte development. Pigment Cell Res 12:13-21. CrossRef Medline

Mayor R, Theveneau E (2013) The neural crest. Development 140:22472251. CrossRef Medline

Mazzone M, Comoglio PM (2006) The Met pathway: master switch and drug target in cancer progression. FASEB J 20:1611-1621. CrossRef Medline

Mujtaba G, Schultz JM, Imtiaz A, Morell RJ, Friedman TB, Naz S (2015) A mutation of MET, encoding hepatocyte growth factor receptor, is associated with human DFNB97 hearing loss. J Med Genet 52:548-552. CrossRef Medline

Naldini L, Weidner KM, Vigna E, Gaudino G, Bardelli A, Ponzetto C, Narsimhan RP, Hartmann G, Zarnegar R, Michalopoulos GK (1991) Scatter factor and hepatocyte growth factor are indistinguishable ligands for the MET receptor. EMBO J 10:2867-2878. Medline

Ohyama T, Groves AK (2004) Generation of Pax2-Cre mice by modification of a Pax2 bacterial artificial chromosome. Genesis 38:195-199. CrossRef Medline

Patuzzi R (2011) Ion flow in stria vascularis and the production and regulation of cochlear endolymph and the endolymphatic potential. Hear Res 277:4-19. CrossRef Medline

Peinado H, Alečković M, Lavotshkin S, Matei I, Costa-Silva B, MorenoBueno G, Hergueta-Redondo M, Williams C, García-Santos G, Ghajar C, Nitadori-Hoshino A, Hoffman C, Badal K, Garcia BA, Callahan MK, Yuan J, Martins VR, Skog J, Kaplan RN, Brady MS, et al. (2012) Melanoma exosomes educate bone marrow progenitor cells toward a prometastatic phenotype through MET. Nat Med 18:883-891. CrossRef Medline

Peng Y, Huentelman M, Smith C, Qiu S (2014) MET receptor tyrosine kinase as an autism genetic risk factor. Int Rev Neurobiol 113:135-165. CrossRef

Pingault V, Ente D, Dastot-Le Moal F, Goossens M, Marlin S, Bondurand N (2010) Review and update of mutations causing Waardenburg syndrome. Hum Mutat 31:391-406. CrossRef Medline

Qiu S, Anderson CT, Levitt P, Shepherd GM (2011) Circuit-specific intracortical hyperconnectivity in mice with deletion of the autism-associated Met receptor tyrosine kinase. J Neurosci 31:5855-5864. CrossRef Medline

Rudie JD, Hernandez LM, Brown JA, Beck-Pancer D, Colich NL, Gorrindo P, Thompson PM, Geschwind DH, Bookheimer SY, Levitt P, Dapretto M (2012) Autism-associated promoter variant in MET impacts functional and structural brain networks. Neuron 75:904-915. CrossRef Medline

Sandell LL, Butler Tjaden NE, Barlow AJ, Trainor PA (2014) Cochleovestibular nerve development is integrated with migratory neural crest cells. Dev Biol 385:200-210. CrossRef Medline

Schmidt C, Bladt F, Goedecke S, Brinkmann V, Zschiesche W, Sharpe M,
Gherardi E, Birchmeier C (1995) Scatter factor/hepatocyte growth factor is essential for liver development. Nature 373:699-702. CrossRef Medline

Schultz JM, Khan SN, Ahmed ZM, Riazuddin S, Waryah AM, Chhatre D, Starost MF, Ploplis B, Buckley S, Velásquez D, Kabra M, Lee K, Hassan MJ, Ali G, Ansar M, Ghosh M, Wilcox ER, Ahmad W, Merlino G, Leal SM, et al (2009) Noncoding mutations of HGF are associated with nonsyndromic hearing loss, DFNB39. Am J Hum Genet 85:25-39. CrossRef Medline

Shah KN, Dalal SJ, Desai MP, Sheth PN, Joshi NC, Ambani LM (1981) White forelock, pigmentary disorder of irides, and long segment Hirschsprung disease: possible variant of Waardenburg syndrome. J Pediatr 99: 432-435. CrossRef Medline

Sonnenberg E, Meyer D, Weidner KM, Birchmeier C (1993) Scatter factor/ hepatocyte growth factor and its receptor, the c-met tyrosine kinase, can mediate a signal exchange between mesenchyme and epithelia during mouse development. J Cell Biol 123:223-235. CrossRef Medline

Steel KP, Barkway C (1989) Another role for melanocytes: their importance for normal stria vascularis development in the mammalian inner ear. Development 107:453-463. Medline

Stern CD (1998) Detection of multiple gene products simultaneously by in situ hybridization and immunohistochemistry in whole mounts of avian embryos. Curr Top Dev Biol 36:223-243. Medline

Tachibana M (1999) Sound needs sound melanocytes to be heard. Pigment Cell Res 12:344-354. CrossRef Medline

Trowe MO, Maier H, Schweizer M, Kispert A (2008) Deafness in mice lacking the T-box transcription factor Tbx18 in otic fibrocytes. Development 135:1725-1734. CrossRef Medline

Trowe MO, Maier H, Petry M, Schweizer M, Schuster-Gossler K, Kispert A (2011) Impaired stria vascularis integrity upon loss of E-cadherin in basal cells. Dev Biol 359:95-107. CrossRef Medline

Trusolino L, Bertotti A, Comoglio PM (2010) MET signalling: principles and functions in development, organ regeneration and cancer. Nat Rev Mol Cell Biol 11:834-848. CrossRef Medline

Tyndall SJ, Walikonis RS (2006) The receptor tyrosine kinase Met and its ligand hepatocyte growth factor are clustered at excitatory synapses and can enhance clustering of synaptic proteins. Cell Cycle 5:1560-1568. CrossRef Medline

Uehara Y, Minowa O, Mori C, Shiota K, Kuno J, Noda T, Kitamura N (1995) Placental defect and embryonic lethality in mice lacking hepatocyte growth factor/scatter factor. Nature 373:702-705. CrossRef Medline

Wu HH, Levitt P (2013) Prenatal expression of MET receptor tyrosine kinase in the fetal mouse dorsal raphe nuclei and the visceral motor/sensory brainstem. Dev Neurosci 35:1-16. CrossRef Medline

Zhang YW, Vande Woude GF (2003) HGF/SF-met signaling in the control of branching morphogenesis and invasion. J Cell Biochem 88:408-417. CrossRef Medline 